\title{
Identidade, Cultura Surda e Produção de Subjetividades e Educação:
}

Atravessamentos e Implicações Sociais

Identity, deaf culture and the building of subjectivity and education: crossings and social implications

Resumo:A questão da identidade é uma das mais caras para a Psicologia. Assim, o objetivo deste trabalho é investigar como a identidade se constitui na presença da surdez. Para tal, realizou-se uma pesquisa de natureza qualitativa, sendo feitas quatro entrevistas com pessoas surdas, enfocando o processo de construção de identidade. Os resultados apontaram a necessidade de os surdos desenvolverem ações afirmativas, consolidando uma comunidade e uma cultura singular. A contribuição deste estudo é mostrar como a condição funcional é importante para a constituição da identidade e também para a organização dos jogos políticos em que vivem os grupos surdos e ouvintes.

Palavras-Chave: Identidade, surdez, movimentos sociais, cultura surda.

Abstract:The issue of identity is one of the most important for Psychology. So, the aim of this paper is to investigate how identity is constituted as confronted with deafness. A qualitative research was done to bring it out. In this study, four interviews were done with deaf people focusing the identity construction process. The results point out the deaf people's need of developing affirmative actions so as to consolidate a singular community and culture. The contribution of this study is to show how important the functional condition is for the constitution of identity, as well as the organization of political games wherein both deaf and hearing groups live.

Key Words: Identity, deafness, social movements, deaf culture.

Eliane Maria Polidoro da Costa

Cromack

Centro de Ciências Biológicas e da Saúde - Curso de Psicologia

Campus Grande

Florianópolis
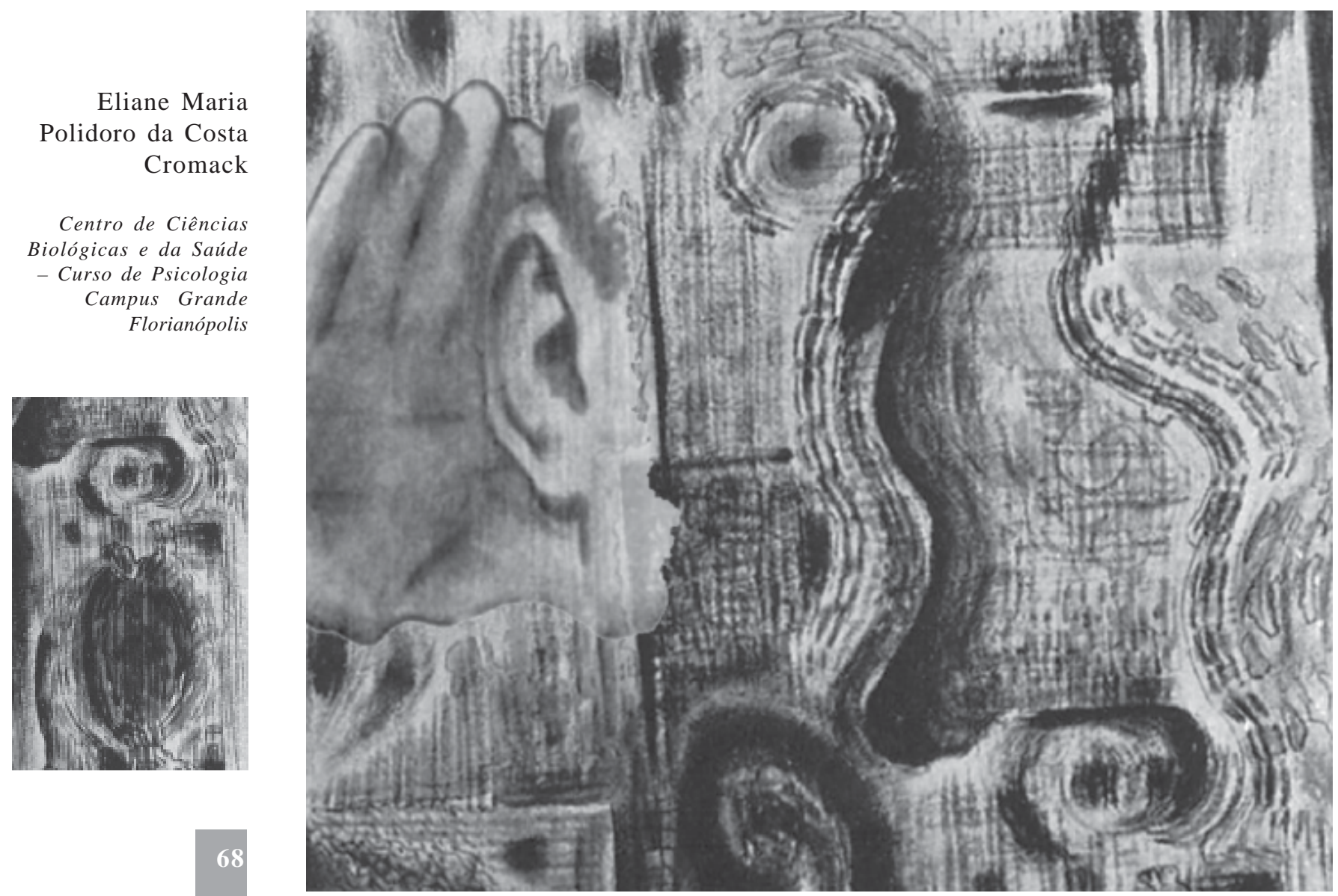
Considera-se, aqui, que a surdez não consiste somente em uma deficiência sensorial, mas, sim, em algo mais complexo, pois conseqüências sociais da condição da surdez podem fazer com que o sujeito não consiga se comunicar com a sociedade de um modo geral, o que causa isolamento e discriminação para com essas pessoas.

A linguagem permeia essa questão, uma vez que é através dela que nos diferenciamos dos outros animais e também assumimos a condição de Seres Humanos, já que é a forma principal de expressão de pensamentos e o instrumento psicológico essencial à constituição das funções psicológicas superiores (Vygotski, 1998).

Frente a esse novo conhecimento, surge o interesse de entender mais qual o papel da linguagem na constituição da identidade de pessoas surdas. Sua organização, cultura e lingüística distintas, considerando o que hoje é chamada de cultura surda ${ }^{1}$, proporciona condições distintas para a constituição da subjetividade e identidade, sendo de interesse desta pesquisa investigá-las.

Pelo fato de os surdos viverem em um mundo completamente visual-gestual, seu cognitivo se desenvolve de um modo totalmente visual, ao contrário dos ouvintes que utilizam a audição para se comunicarem, o que instiga reflexões sobre a constituição do sujeito. Por viverem em uma comunidade onde são minoria, as chances de ocorrer uma comunicação imprópria são grandes e, caso isso ocorra, haverá conseqüências para o crescimento intelectual, social e emocional dessa pessoa. A aquisição de uma linguagem, no caso a de sinais, é de extrema importância para o desenvolvimento de uma identidade pessoal surda. Somos seres sociais e, por isso, precisamos identificar-nos com uma comunidade social específica e, com ela, interagir de modo pleno, ou seja, precisamos de uma identidade cultural, e, para isso, não basta uma língua e uma forma de alfabetização, mas, sim, um conjunto de crenças, conhecimentos comuns a todos.

Tendo como conceito de identidade cultural um conjunto de características que definem um grupo e que incidem na construção do sujeito, sejam elas as que identificam ou as que excluem (Perlin, 1998, p. 53), o surdo se constitui dentro de um espaço social onde se vê como parte diferente do mesmo. Esse espaço social, que vamos chamar de cultura ouvinte, criou, historicamente, um estereótipo de incapacidade, de deficiência, para o surdo.

O estereótipo sobre o surdo jamais acolhe o ser surdo, faz com que as pessoas se oponham, às vezes disfarçadamente, e evite a construção da identidade surda, cuja representação é o estereótipo da sua composição distorcida e inadequada (Perlin, 1998, p. 54).

Muitas vezes, o sujeito surdo transita entre essas duas culturas, a surda e a ouvinte; no entanto, sua identidade se constitui com a consciência de ser definitivamente diferente por necessitar de recursos completamente visuais. Essa oscilação entre os surdos e os ouvintes faz com que o sujeito surdo constitua, por vezes, sua identidade de forma fragmentada.

Skliar (1998, p. 66) chama esse processo de identidade flutuante, onde o surdo não está a serviço da comunidade ouvinte por falta de comunicação e nem a serviço da comunidade surda por falta da língua dos sinais. É o sujeito surdo construindo sua identidade com fragmentos das múltiplas identidades de nosso tempo, não centradas, mas sem um elemento integrador como a linguagem e sua capacidade de significação.

Contudo, o estudo dos surdos mostra que boa parte do que é distintivamente humano no homem, suas capacidades de linguagem, pensamento, comunicação e cultura - não se desenvolvem de maneira automática, não se compõem apenas de funções biológicas, mas também têm origem social e histórica; essas capacidades são, como diz Sacks, um presente - o mais maravilhoso dos presentes de uma geração para outra (Sacks, 1998, p. 11). Nesse sentido, realizou-se uma pesquisa na qual se investigou a construção da identidade na presença da surdez congênita, com o objetivo de verificar as características do processo de construção da identidade na presença da surdez bem como de identificar a importância das características do universo cultural e lingüístico da pessoa surda como fator de construção da identidade.

Cumpre esclarecer que existe, ainda, um número muito pequeno de pesquisas realizadas na área de deficiência, em particular na deficiência auditiva. Frente a esse quadro, verifica-se a necessidade de maior dedicação a essa parcela da sociedade, tanto em termos de políticas quanto em termos científicos.

Na Psicologia, verifica-se a ausência de estudos com as pessoas surdas, já que, na Psicologia, em geral, pensa-se, por exemplo, o conceito de identidade supondo a condição de normalidade. Há muitos estudos sobre a identidade, mas ainda muito pouco sobre a identidade e a surdez. Diante disso, faz-se necessário avançar no estudo desse conceito em sua articulação com a questão da presença de condições adversas ao desenvolvimento psicológico considerado 'normal'.
1 Conforme Sacks (1998) a condição surda é muito mais complexa do que uma deficiência sensorial, pois trata-se de um modo singular de se colocar no mundo, uma linguagem, um conjunto de crenças, valores, costumes distintos, constituindo, assim, uma cultura surda. 
A atualidade do tema desta pesquisa é destacada, dado o fato de a organização política dos surdos ser um fato recente bem como a argumentação por parte da literatura e da comunidade surda quanto à existência da cultura surda. A Psicologia Social, nesse sentido, em sua vocação interdisciplinar, pode permitir maior compreensão de todos esses processos, na medida em que problematiza a interface entre as dimensões intersubjetivas e subjetivas. É com esse olhar da Psicologia Social que se pretende contribuir para a análise dessa questão, com especial foco na construção da identidade normal, incluindo-se, aí, a condição da surdez.

\section{Pistas Conceituais: Identidade, Linguagem e Constituição do Sujeito}

A identidade implica o processo de consciência de si próprio, sendo que esta ocorre por meio de relações intersubjetivas, de comunicações lingüísticas e experiências sociais, tornando-se um processo ativo (Doron e Parot, 2001).

Desse modo, a identidade, em uma perspectiva social, é realizada no espaço das relações, tratando-se de um processo dinâmico, ou seja, [...] um processo contínuo de construção e desconstrução, na ambigüidade presente e inevitável que a compõe, implicando um trabalho de unificação de diversidade, incorporando a diferença” (Maheirie, 1994, p. 65).

Segundo Silva (2000, p.80), a característica da linguagem tem conseqüências importantes para a questão da diferença e da identidade cultural. Considerando que a diferença primordial dos surdos permeia a questão da linguagem, pode-se perceber o quanto a constituição da identidade é marcada por essa dimensão lingüística, fazendo com que essa diferença seja concebida como autoreferenciada e dotada de sentido nas trocas sociais. Partindo disso, torna-se fundamental compreender as relações culturais e sociais que constituem a identidade das pessoas. Conforme Guareschi (2000, p. 111),

2 As funções psicológicas superiores são mediadas semioticamente; sua estrutura se pauta pela utilização da imaginação dos signos como meios auxiliares e/ou instrumento-chave das capacidades de auto-regulação.
Dentro do cenário econômico, político e cultural, o processo de construção de identidades sociais e culturais vem sofrendo uma série de conflitos, principalmente por parte dos grupos com identidades não reconhecidas socialmente, isto é, identidades discriminadas, marginalizadas ou oprimidas por setores dominantes ou elitizados da sociedade [...]. Isso faz com que essas pessoas busquem articulações de poder e de defesa dos seus direitos de cidadania através de movimentos autônomos, ou desvinculados do Estado.
Frente a isso, percebe-se a relevância do processo no qual os surdos estão passando para a constituição da identidade, ou seja, o processo de construção de políticas afirmativas, que marcam o espaço dos surdos não como seres subalternos em relação à sociedade ouvinte, mas, sim, como membros de uma cultura singular, para que não seja marginalizado, mais uma vez, seu modo de se colocar no mundo. Assim, tais políticas afirmativas lutam contra todo tipo de subordinação que existe no contexto das trocas sociais.

Ao se abordar o conceito de identidade, trabalhase aqui com a noção - pautada pela Psicologia Histórico-cultural - de que se trata de um processo cuja expressão se dá tanto no plano intra-subjetivo quanto intersubjetivo, sendo esses planos mutuamente constitutivos, em estreita relação e dialeticamente articulados (Vigotski, 1993).

Tendo-se como pressuposto que a identidade é um fenômeno dinâmico e social, ou seja, ocorre por intermédio das relações interpsicológicas, abrangendo, então, experiências sociais e modos de comunicação, o pertencimento a um grupo social com uma forma característica de linguagem é de extrema importância para a constituição do sujeito. Uma vez que o termo linguagem tem um sentido bastante amplo, a linguagem é tudo que envolve significação, que tem um valor semiótico ${ }^{2}$ e não se restringe apenas a uma forma de comunicação. É pela linguagem que se constitui o pensamento verbal do indivíduo. Assim, a linguagem está sempre presente no sujeito, mesmo no momento em que este não se comunica com outras pessoas. A linguagem constitui o sujeito, a forma como este recorta e percebe o mundo e a si próprio (Goldfeld, 2002; Góes, 1999; Vygotski, 1996).

Na pessoa surda, não é diferente; o que muda é que a linguagem deixa de ser sustentada em fonemas, letras, palavras, enfim, em sons, e passa a se sustentar em sinais imagéticos, que são signos lingüísticos para os surdos da mesma forma que as palavras são para os ouvintes. Sacks (1998), inclusive, em seu livro sobre surdez, propõe um trocadilho com a condição ouvinte e intitula seu livro "Vendo Vozes".

No entanto, essa visão em relação à condição surda é relativamente nova. Somente a partir da década de 80 , percebeu-se a necessidade de reconhecer o verdadeiro valor da cultura e da linguagem surda para o desenvolvimento dos surdos.

Em pessoas surdas, por viverem uma grande ruptura lingüístico-comunicativa entre o mundo surdo e o ouvinte, existem dificuldades para o desenvolvimento cultural; por isso, é necessário 
que se construam meios especiais para a sua realização, como, por exemplo, a Libras ${ }^{3}$.

No entanto, dentro do universo ouvinte, a condição da surdez é vista como categoria estereotipada, uma vez que a diferença acaba por se sobrepor à semelhança de serem todos seres humanos.

É também partindo desse estereótipo social que o sujeito surdo se constitui, afirmando-se e/ou opondo-se dialeticamente, ou seja, é com base nas significações produzidas através das relações sociais, envolvendo esta, em grande parte, a relação com os ouvintes, que o surdo constrói seu autoconceito. Essa significação não se dá somente pelo que verbaliza ou deixa de verbalizar, seja isso concretizado por sons ou gestos, mas também pelo lugar social que é atribuído a essas pessoas nas relações e pelas situações de desvantagem a que são submetidas numa cultura hegemonicamente auditiva.

Porém, não se deve considerar somente o lado quantitativo, ou seja, não é porque o surdo constitui minoria na sociedade, que vive em uma situação de desvantagem social, de desigualdade na vida da sociedade majoritária. Existe uma questão bem mais ampla do que isso, que é o lado qualitativo, que diz respeito ao modo próprio de a pessoa surda constituir-se e apropriar-se da cultura humana. Considerando esse lado qualitativo, percebe-se que a discriminação para com o surdo, como para com a utilização da linguagem de sinais, corresponde, acima de tudo, a uma hierarquia social cuja lógica é exclusora das diferenças.

\section{Percorrendo Historicamente o Processo Educacional dos Surdos}

A forte ênfase no papel da linguagem verbal no funcionamento cognitivo humano gerou distintas representações, principalmente no caso dos surdos, uma vez que a dificuldade encontrada por eles na linguagem foi vista, por vezes, como geradora de obstáculos ao desenvolvimento do pensamento. Um desses obstáculos seria o de que a linguagem de sinais levaria a uma redução no universo intelectual ao mundo concreto, restringindo, assim, as funções de caráter abstrato. Por isso, o oralismo dominou em todo o mundo até a década de 1970. Porém, segundo Góes (1999, p.26), as discussões teóricas sobre cognição e linguagem começaram a alterar-se a partir da década de 80 , com base em outros aportes, tais como a teoria de L. S. Vygotski. Com isso, passa a expandir-se uma nova proposta, que parte do pressuposto que a comunicação deve ser privilegiada e não a língua propriamente dita. Assim, a deficiência não torna a criança um ser que tem possibilidades a menos, ou seja, ela tem possibilidades diferentes, e não menores (Góes, 1999, p. 34).

Partindo disso, entra em questão um novo fator, pois, junto com uma língua distinta para os surdos, surge também uma nova cultura, ou seja, junto ao bilingüismo, veio o biculturalismo, revelando um processo antes ignorado, que é o processo de construção da identidade cultural surda, uma vez que o surdo tem contato com dois grupos culturais distintos, o ouvinte e o surdo. Assim sendo, estréia uma nova tendência, a de vincular o processo educacional às experiências culturais dos surdos, para que seu desenvolvimento alcance maior êxito. Como conseqüência, a discussão sobre as formas de atenção às pessoas e aos grupos surdos tem sido deslocada do campo da educação especial para o campo antropológico, pois a educação deveria dar acesso aos bens culturais de acordo com as características singulares decorrentes da surdez.

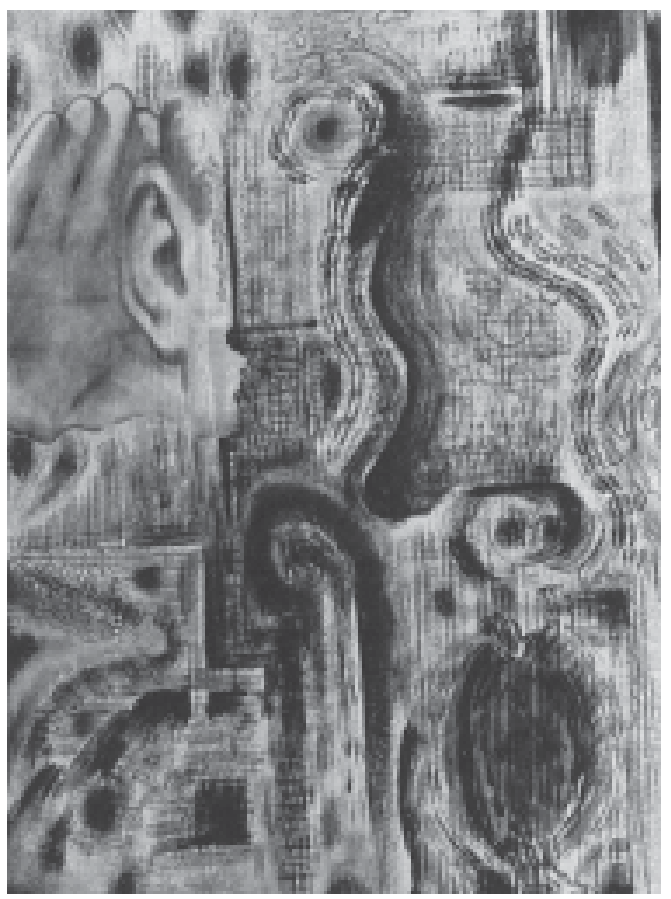

"Dentro do cenário econômico, político e cultural, o processo de construção de identidades sociais $e$ culturais vem sofrendo uma série de conflitos, principalmente por parte dos grupos com identidades não reconhecidas socialmente, isto é, identidades discriminadas, marginalizadas ou oprimidas por setores dominantes ou elitizados da sociedade [...]. Isso faz com que essas pessoas busquem articulações de poder e de defesa dos seus direitos de cidadania através de movimentos autônomos, ou desvinculados do Estado."

Mesmo com todo esse processo de luta pelo direito à diferença, ou seja, por uma política afirmativa da cultura surda, no atendimento educacional ainda se faz presente, em menor escala, a dominação da oralização, seja ela na prática ou na memória dos que vivenciaram essa dominação.

A partir desses referenciais teóricos, realizaram-se entrevistas para se dar voz aos sujeitos que encarnam esses processos sociais, valorizando seu testemunho de construção identitária. Foram entrevistados quatro jovens surdos, com idade entre 
23 e 24 anos, de ambos os sexos, com surdez prélingüística ou congênita, estudantes do Curso de Pedagogia à Distância da Universidade do Estado de Santa Catarina - UDESC, que possui uma turma exclusiva para surdos. Para preservação dos mesmos, serão denominados sujeitos A, B, C e D. Essas entrevistas se deram através da mediação de duas tutoras do curso de Pedagogia da UDESC, que possibilitaram o primeiro contato com os surdos e também se disponibilizaram como intérpretes durante as entrevistas, o que permitiu uma comunicação entre entrevistados e pesquisadora. A escolha dos sujeitos se deu por recomendações pessoais, sendo essa técnica também conhecida pela Antropologia como network.

Tem essa diferença, porque houve todo um passado histórico.

$O$ surdo tem um certo trauma do que se passou historicamente, de como foi a história dele, a defesa da língua de sinais... Já teve uma proibição que foi uma coisa muito marcante e então isso aí tudo reflete no jeito de pensar: 'não, surdo não precisa oralizar', 'não é importante o oral', 'o importante é conseguir se comunicar, conseguir passar o que está querendo nos entender'.
Na análise dos dados, foi utilizada também a metodologia de análise de conteúdo, conforme Franco(1996). Essa autora dá indicativos para a construção de categorias a posteriori a partir do estudo exaustivo das entrevistas, do qual se destacam regularidades. Tais pontos em comum das entrevistas, por sua vez, constituem as categorias de análise expostas a seguir.

\section{Seguindo as Pistas}

Na tentativa de responder às questões norteadoras da presente pesquisa, como: Qual a importância do tipo de universo cultural e lingüístico na constituição da identidade de pessoas surdas? Ou ainda, como se dá o contraste entre a cultura surda e a cultura ouvinte no processo de construção da identidade, é que se deu maior atenção a alguns temas de grande relevância na coleta de dados. No conjunto dos dados coletados, pôde-se verificar a diversidade no interior dos grupos surdos, bem como as diferentes maneiras como eles lidam e encaram os surdos oralizados, os que se comunicavam somente pela Libras e os que eram bilingües.

Esse processo fica claro na fala de uma das entrevistadas, que conheceu a Libras com vinte e dois anos e, até então, só se comunicava através da oralização.

Tem essa diferença, porque houve todo um passado histórico. O surdo tem um certo trauma do que se passou historicamente, de como foi a história dele, a defesa da língua de sinais... Já teve uma proibição que foi uma coisa muito marcante e então isso aí tudo reflete no jeito de pensar: 'não, surdo não precisa oralizar', 'não é importante o oral', 'o importante é conseguir se comunicar, conseguir passar o que está querendo nos entender'. Não é uma preocupação de entender o que o ouvinte quer dizer, é uma preocupação de entender o que o colega surdo quer dizer, a comunicação fica bem ali, entende? Não há preocupação em participar da comunidade ouvinte, no meu modo de ver, é isso(sic, sujeito A, 23 anos, sexo feminino).

Essa mesma experiência foi encontrada no relato de uma surda, Silvia Sabanovaite, no livro Do Sentido...Pelo Sentido...Para o Sentido: Sentido das Pessoas com Deficiência Sensorial (2002, p. 47), que, em seu depoimento, discute que:

Recebi uma educação puramente oralista...Aos dezessete anos foi conhecer uma associação de surdo, através de um amigo. No primeiro dia, fiquei bastante chocada, pois não esperava encontrar pessoas diferentes de mim. Levei muito tempo para aceitar essa forma de comunicação e não conseguia entender o porquê deles utilizarem este meio. Não pensem que fui bem recebida. Eles não me aceitaram bem por ser oralizada e desconhecer totalmente a Língua de Sinais, o que, para a comunidade surda, é inadmissível.

Nos depoimentos em questão, verifica-se que a diversidade dentro da comunidade surda se dá pautada em dois fatores que, na realidade, são intrínsecos, o grau de deficiência auditiva e o meio utilizado pelo surdo para se comunicar. Assim, algo que despertou o interesse da pesquisadora, ao desenvolver a análise, foi o fato de que o posicionamento político de cada entrevistado ou entrevistada se dava a partir de sua relação com a oralização bem como a partir de sua condição funcional (surdez severa ou profunda). De acordo com o que se obteve aqui, o que pode ser observado, nos depoimentos acima, os oralizados, muitas vezes, não defendem a mesma postura de ruptura com o mundo ouvinte que aqueles não oralizados.

Desse modo, esses fatores estão relacionados com um maior engajamento na política afirmativa da comunidade surda, ou seja, dentro da cultura surda, considera-se que os oralizados (principalmente aqueles que não conhecem a língua de sinais), em geral, não são surdos profundos e acabam não sendo tão engajados na políticas afirmativas se comparados, pelo menos em nossos dados, com os surdos não oralizados, não sendo aqueles considerados de imediato pessoas inerentes à comunidade surda. Trata-se de um jogo complexo, onde postura política e condição funcional/comunicacional se atravessam, trazendo novos desafios à compreensão dos movimentos sociais e ao processo de construção da identidade.

A comunidade surda, por sua vez, pode identificar simbolicamente a posição política de acordo com o histórico e a intensidade da condição surda. Uma pessoa com surdez intensa e que, ao longo da 
vida, tenha passado pelo processo de oralização, vivenciando-o como uma experiência árdua, uma vez que esta não lhe trouxe melhor desenvolvimento, pelo contrário, trouxe-lhe um estigma de deficiente, de incapaz, nela, o engajamento com as questões políticas está mais presente. Por outro lado, aqueles cuja vivência com a oralização não se tenha dado de forma tão problemática, em função de sua condição auditiva restrita, mas suficiente para relacionar-se com os sons dos fonemas de maneira um pouco mais tranqüila, nesses, a postura política se relativiza e a relação com os ouvintes é menos marcada por tensões.

Para se compreender esse processo, pode-se fazer referência aos que passaram por outros movimentos sociais. Muitos deles rompem com os grupos hegemônicos para reverter uma história de exclusão, como se verificou no movimento feminista, por exemplo. Se, a princípio, é preciso romper com aqueles que representam a hegemonia e o poder neste caso, os ouvintes - essa necessidade de afirmação decorre do processo histórico de imposição de um modo de comunicar e de uma cultura ouvinte que agora é vista de maneira negativa pelos surdos que vivenciaram negativamente a oralização. Assim,

A afirmação da diferença pode vir a favorecer discriminações e atitudes de estranhamento e separação com relação ao outro, favorecendo a formação de mentalidade e sociedades excludentes. [...] Uma das conseqüências desse processo é o que poderíamos chamar de "guetização" [...]. Guetização fomentada e incentivada pelas próprias minorias, mediante a busca de construção e de reconhecimento de identidades singulares (e do "orgulho" dessas identidades) [...]. Se, nesse processo de "guetização", há elementos de ressentimentos e revidação, também há o viés de resistência à violência, discriminação e inferiorização sofrido, como momento e estratégia de suas lutas sociais, pela construção e pelo reconhecimento de identidades, bem como mediante a inclusão (Kauchakje, 2003, p. 71).

O que a autora chama a atenção é justamente para a questão que acima foi levantada, ou seja, pode-se compreender as diferenças em termos políticos no interior dos grupos surdos a partir das diferentes vivências que cada um dos surdos possui em relação à oralização e à cultura ouvinte, o que remete às suas histórias singulares de relação com esse mundo. Salienta-se a importância disso para o processo de construção da identidade que, como foi discutido anteriormente, se dá estreitamente vinculado às diferenças mas também aos valores atribuídos a essas diferenças.
A oralização, para os surdos que defendem as políticas afirmativas, representa, hoje, um modo de relação na qual os surdos vivem valores em que sua diferença é vista como desvantagem, como uma espécie de 'menos valia'. Ser oralizado, para muitos deles, é assumir esse lugar social do diferente deficiente, do diferente de menor valor. Assim, tratase de assumir uma diferença - a surdez - mas negar seu valor negativo através da imposição de novos sentidos à condição de surdez, que agora é ressignificada como uma cultura singular, um modo de vida particular que possui o mesmo valor que aquele dos ouvintes. Como conseqüência, para alguns, é preciso romper com o mundo ouvinte e valorizar a relação com os pares e a sua forma de comunicação singular, a Libras.

Com o reconhecimento da diferença, como tendo igual valor, surge a necessidade de uma discussão a respeito do processo de inclusão e/ou integração, sendo que essa discussão está vinculada diretamente à forma como se dá o processo e o respeito ao surdo durante o processo de inclusão e/ou integração. Isso fica evidente em algumas falas, como:

A inclusão só vai ser boa se existir o respeito à diferença que não existe hoje, e a integração, o que me parece, é que integração é apenas estar ali no meio, seja ouvinte, surdo, o que for, mas também não há enfatização das características que ele tem, as diferenças, porque o surdo tem uma maneira diferente de aprender, Agora, se os ouvintes vão aceitar, alguns sim, outros não, por terem uma mentalidade diferente, então a questão não é nem separar como muita gente pensa, a questão é só respeitar a diferença, e essa questão, o que eu vejo, melhor assim para mim não tem um melhor que o outro, os dois são quase a mesma coisa(sic, sujeita A, 23 anos, sexo feminino).

Perante esse depoimento, percebe-se que o enfoque dado, quando remete à educação do surdo, permeia, principalmente, a questão do desenvolvimento da criança surda, ligado diretamente ao respeito à diferença, uma vez que essa diferença gera a necessidade de um processo educativo singular. Caso isso não ocorra, o surdo é extremamente prejudicado em seu desenvolvimento tanto educacional quanto emocional, já que, em decorrência da não aprendizagem, o surdo leva o estigma de incapaz. Diante desse fato, tal questão envolve também um processo político, na medida em que essa diferença resulta em situações de desvantagem numa cultura hegemonicamente ouvinte.

A política de integração trouxe muito desse prejuízo, citado acima, ao desenvolvimento da pessoa surda, não apenas no âmbito da Educação, mas também 
na construção de sua identidade, uma vez que a política de integração leva o sujeito, todo o tempo, a viver situações em que ele se vê como fracassado, já que essa política não respeita a diferença entre o ouvinte e o surdo, fazendo com que o surdo tenha o ouvinte como ideal. Segundo Skliar (1998, p. 11), essa política educativa é de natureza discriminatória, descontínua, anacrônica, conduzindo a uma prática permanente de exclusão [...]; é um espaço habitual onde se produzem e se reproduzem táticas e estratégicas de naturalização dos surdos em ouvintes, e o local onde a surdez é disfarçada.

o contato com a oralização, com mundo ouvinte na aprendizagem como

'perda de tempo', como ruptura constante, como

incompreensão. $\mathrm{Na}$ escola, ficavam só copiando não se aprende nada...O surdo oralizado anda atrás do ouvinte, nunca vai ser igual... (sic, sujeita A, 23 anos, sexo feminino).

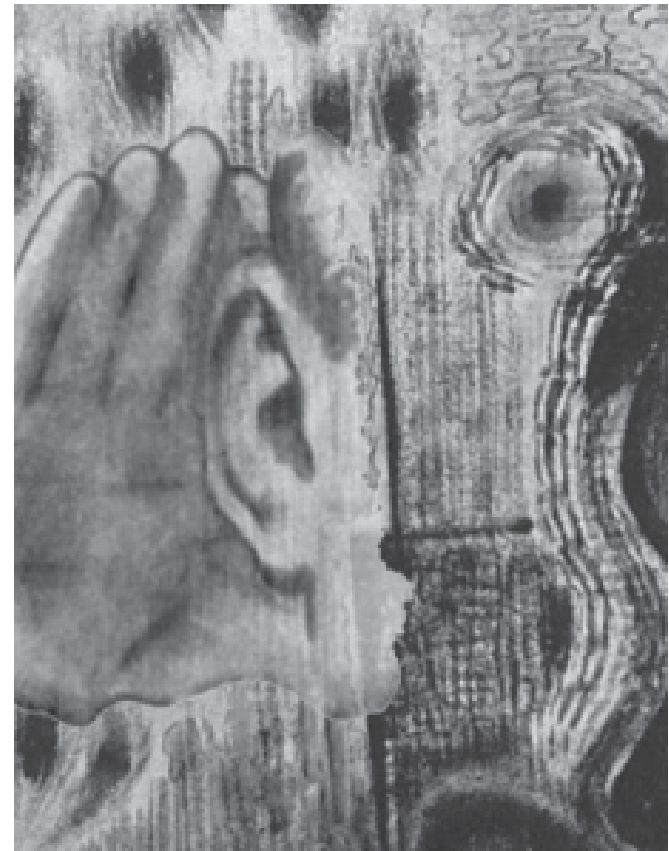

Essa questão da integração como processo de exclusão fica muito clara em algumas falas, como: o contato com a oralização, com mundo ouvinte na aprendizagem como 'perda de tempo', como ruptura constante, como incompreensão. Na escola, ficavam só copiando não se aprende nada...O surdo oralizado anda atrás do ouvinte, nunca vai ser igual... (sic, sujeita A, 23 anos, sexo feminino).

Então, nessa perspectiva, o surdo será sempre 'menos' que o ouvinte, está sempre na desvantagem, sempre no esforço de adaptar-se às condições dos ouvintes. Por tudo isso, a integração foi considerada um fracasso, uma vez que não proporciona melhor desenvolvimento educacional e emocional ao sujeito surdo, mas, sim, um estigma de deficiente que tem que lutar para ser igual ao ouvinte, que seria o modelo ideal.

Do mesmo modo que outros grupos sociais que vivem a exclusão e o preconceito cotidianos, os surdos começam a se organizar há mais ou menos quinze anos , procurando construir novas políticas identitárias, as quais vão encontrar, na perspectiva de inclusão social, uma ideologia a ser fomentada por seu movimento político. Assim, entendendo a inclusão como um movimento dinâmico que parte do reconhecimento da diferença contemplandoa na construção do espaço social, seria ela a "política ideal" para um melhor desenvolvimento do surdo. Porém, esse direito não é atualmente colocado na íntegra (Sacks, 1998), pois de que adianta os surdos terem os mesmos direitos, acesso ao espaço e tempo escolar que os ouvintes, mas terem que se submeter à sua dinâmica de funcionamento, ou seja, ao oralismo? Nesse sentido, a inclusão só daria resultados positivos se fosse além dos direitos iguais e alcançasse o respeito à diferença. Caso esse respeito à diferença não exista, dar-se-á margem ao processo de exclusão, uma vez que esse aluno surdo, dentro de uma sala de aula com vinte ou trinta alunos ouvintes, não irá acompanhar os colegas em face da ausência de atenção especial para sua singularidade.

Segundo Kauchakje (2003, p. 75), no campo teórico, os direitos à igualdade e à diferença apresentam fortes antagonismos, mas, na realidade social, tanto ao se tratar da relação com a inclusão quanto com processos de exclusão social, eles aparecem imbricados e adquirindo sentidos que se tocam.

Em outros depoimentos, encontram-se posições mais radicais quanto à crítica ao princípio de integração, confirmando, mais uma vez, o que foi levantado anteriormente quando se refere ao convívio com os ouvintes e ao engajamento na política afirmativa do surdo, ou seja, os entrevistados que tiveram um relacionamento mais efetivo com o mundo ouvinte se posicionam de maneira também menos radical, porém sem deixar de defender seus direitos. No entanto, aqueles, para os quais o relacionamento com os ouvintes e com o processo educativo dos ouvintes (escolas regulares) foi mais dramático, têm uma postura mais inclusiva, como se pode perceber nas seguintes entrevistas:

[...] tem as duas, a inclusão precisa uma escola própria para o surdo porque é mais fácil, tem professor surdo, aluno surdo, é o direito do surdo, já a outra a integração é uma união surdo-ouvinte, mas o surdo fica muito preocupado porque para o ouvinte é sempre mais fácil. Na minha opinião o ouvinte pode aprender a libras e tem uma troca com o português, precisa de uma interação entre o surdo e o ouvinte, por exemplo, em uma escola própria para ouvintes, tem vários alunos ouvintes e dois surdos, mas o professor é ouvinte e vai virar para o lado, escrever no quadro e o aluno surdo não vai entender nada. Falta o ouvinte, todos precisam 
aprender a língua dos sinais para ajudar o surdo, também o surdo quer aprender o português para haver uma troca, mas primeiro tem que ter uma escola própria para surdos é bem mais fácil ele conseguir desenvolver mais rápido. Ainda existe a influência do ouvinte, o surdo se preocupa com a dominação do ouvinte, o surdo já é traumatizado, nessas escolas ele perdeu muito, não desenvolveu(sic, sujeito $B, 26$ anos, sexo masculino).

Em outra entrevista, também se fez presente essa discussão:

Neste caso seria melhor a inclusão, que faz com que as pessoas possam crescer, que possa fazer com que elas tenham aprendizagem e não fiquem na mesmice, que possam lutar pelas questões e seus objetivos (sic, sujeita $C, 26$ anos, sexo feminino).

Diante do exposto acima, fica evidente a maior tendência dos entrevistados em assumir uma postura inclusiva como seu modelo de participação educativa e social. Acrescenta-se que

Para os grupos minoritários, em particular os surdos, a inclusão diz respeito ao exercício de direitos, tais como acesso à cidade, aos equipamentos de educação, ao trabalho, à assistência e previdência social, à saúde, ao lazer e à cultura. Sobretudo, diz respeito não apenas à participação no cenário social já dado (instituições, estruturas de poder, cultura etc), mas sim à participação na sua (re) configuração e (re) construção para que novos direitos relativos à diversidade sejam incorporados (Kauchakje, 2003, p. 67).

Assim, faz-se necessário discutir a importância de tal fato para este estudo, ou seja, para se compreender o processo de construção da identidade, não se poderia deixar de lado o atual contexto político de que compartilham os surdos, especialmente aqueles organizados em associações, que têm levado às instituições seu posicionamento. Essa tendência à defesa da inclusão tem gerado a necessidade de criação de salas de aulas exclusivas para surdos como forma de superar as políticas anteriores, que resultaram fracassadas. A conseqüência disso será, certamente, o fortalecimento da identidade dos surdos como grupo cultural específico, não só pelas conquistas que seu movimento tem produzido mas também pelo fato de proporcionar maior convivência destes com seus pares.

Frente a isso, percebe-se o quanto a identidade das pessoas se constitui com base no jogo de identidade e diferença (Silva, 2000), uma vez que é a partir do outro que o autoconceito se produz, ou seja, é a partir das relações sociais que cada um se reconhece como um sujeito singular e, nesse caso, a diferença é aquilo que o outro é que eu não sou, já que, à medida que afirmamos ser surdos, estamos, automaticamente, negando a condição ouvinte, por exemplo. Com isso, a constituição de identidade não pode ser compreendida como um processo natural, mas, sim, um processo cultural em constante movimento.

Considerando-se a construção da identidade uma produção social, supõe-se também que esteja interligada com as relações de poder. Como destacado nas considerações teóricas, a identidade, tal como a diferença, é uma relação social. Isso significa que sua definição - discursiva e lingüística - está sujeita a vetores de força, a relações de poder. Logo, para os surdos, essa relação identidade diferença está interligada com a hegemonia da cultura ouvinte, sendo que esta, por ser a maioria, sobrepõe-se à cultura surda. Em face disso,

A identidade e a diferença estão estreitamente associadas a sistemas de representação [...] como tal, a representação é um sistema lingüístico e cultural: arbitrário, indeterminado e estreitamente ligado a relações de poder. [...] Questionar a identidade e a diferença significa, neste contexto, questionar os sistemas de representação que lhe dão suporte e sustentação(Silva, 2000, p. 89).

No entanto, essa relação de poder entre a identidade e a diferença implica sempre operações de incluir e excluir, de modo que se compreende a luta da comunidade surda pelo seu direito à inclusão, porém respeitando a diferença existente, já que a afirmação de uma identidade sempre demarca fronteira, fazendo uma distinção entre o eu e o outro.

\section{Considerações Finais}

A aproximação proporcionada pelos discursos dos sujeitos leva a discussões pertinentes ao âmbito político, psicológico, social e antropológico, uma vez que a singularidade existente nos sistemas de trocas lingüísticas proporciona uma cultura, enquanto valores, crenças e formas de organização das trocas sociais, aspectos estes distintos da maioria ouvinte, havendo, assim, a formação de duas culturas ao mesmo tempo semelhantes e antagônicas.

No entanto, a cultura e a comunidade surda, por se tratar de dimensões inseridas na cultura hegemônica, que é a ouvinte, foram e são formadas, ainda hoje, com base na exclusão imposta pelo mundo ouvinte, como também com base nos valores negativos propostos a essa diferença. A cultura surda, no entanto, começou a expandir-se não somente no âmbito educacional, ou seja, não
Para os grupos minoritários, em particular os surdos, a inclusão diz respeito ao exercício de direitos, tais como acesso à cidade, aos equipamentos de educação, ao trabalho, à assistência e previdência social, à saúde, ao lazer e à cultura. Sobretudo, diz respeito não apenas à participação no cenário social já dado (instituições, estruturas de poder, cultura etc), mas sim à participação na sua (re) configuração e (re) construção para que novos direitos relativos à diversidade sejam incorporados (Kauchakje, 2003, p. 67). 
mais como uma língua diferente, mas também por conhecimentos e crenças comuns que auxiliaram na constituição de uma cultura própria. Então, a constituição da identidade dos surdos passa pela mudança de paradigma da deficiência para o de minoria lingüística e cultural (Kauchakje, 2003).

Conviver com aqueles que compartilham uma condição funcional acaba, assim, fortalecendo os processos identitários que têm marcado essas novas configurações do movimento de surdos, sendo algo de fundamental importância para o reconhecimento social da cultura surda.

No entanto, apesar da luta constante da comunidade surda pelo respeito e aceitação como grupo cultural distinto, ainda há uma dificuldade muito grande de desenvolvimento, da inclusão dos surdos com base no respeito a suas diferenças. Há que se considerar, por exemplo, que a maioria das crianças surdas são filhos de pais ouvintes, o que, em seu desenvolvimento, proporciona maiores dificuldades, dado que essa condição leva à presença de rupturas no processo de comunicação entre pais e filho surdo. Tais rupturas, por sua vez, acarretam, às vezes, problemas de ordem social e cognitiva cuja expressão é muito mais o resultado da incapacidade dos ouvintes em assumir formas de comunicação e intervenção que considerem as particularidades da surdez do que devido a dificuldades inerentes à ausência de audição.
Partindo disso, é fundamental que instituições escolares, os pais, enfim, o sistema de interrelacionamento que rodeia a criança surda, preocupem-se em entender o modo pelo qual ela se comunica para que as trocas possam existir de forma satisfatória para ambas as partes.

É preciso eliminar o leito de procusto ${ }^{4}$ a que os surdos foram submetidos, ou seja, é necessário, para um adequado desenvolvimento tanto físico quanto psíquico, que a cultura hegemônica deixe de se considerar modelo de perfeição e passe a perceber que o pluralismo não significa inferioridade. Com esse novo olhar, não seria mais preciso que o sujeito surdo sofresse um atraso em seu desenvolvimento em decorrência da adequação ao modelo hegemônico.

A condição funcional dos sujeitos é parte constituinte não só de sua identidade mas também de como esse processo atua nas formas de organização política e social de um grupo minoritário. Logo, ressalta-se a importância do reconhecimento da diferença não como algo de menor valor em relação ao que é compartilhado pelos grupos hegemônicos, mas, sim, como algo intrínseco e singular do sujeito, pois é com base nessa diferença que o surdo se constitui.
4 Conta esse mito grego que havia uma pousada no meio do deserto na qual o proprietário tinha uma condição para hospedar os visitantes: que coubessem em seu leito. Caso não se adequassem, ou se cortavam as pernas ou se esticavam os membros da pessoa em instrumentos de tortura, de modo a enquadrá-los à força no padrão físico da cama.

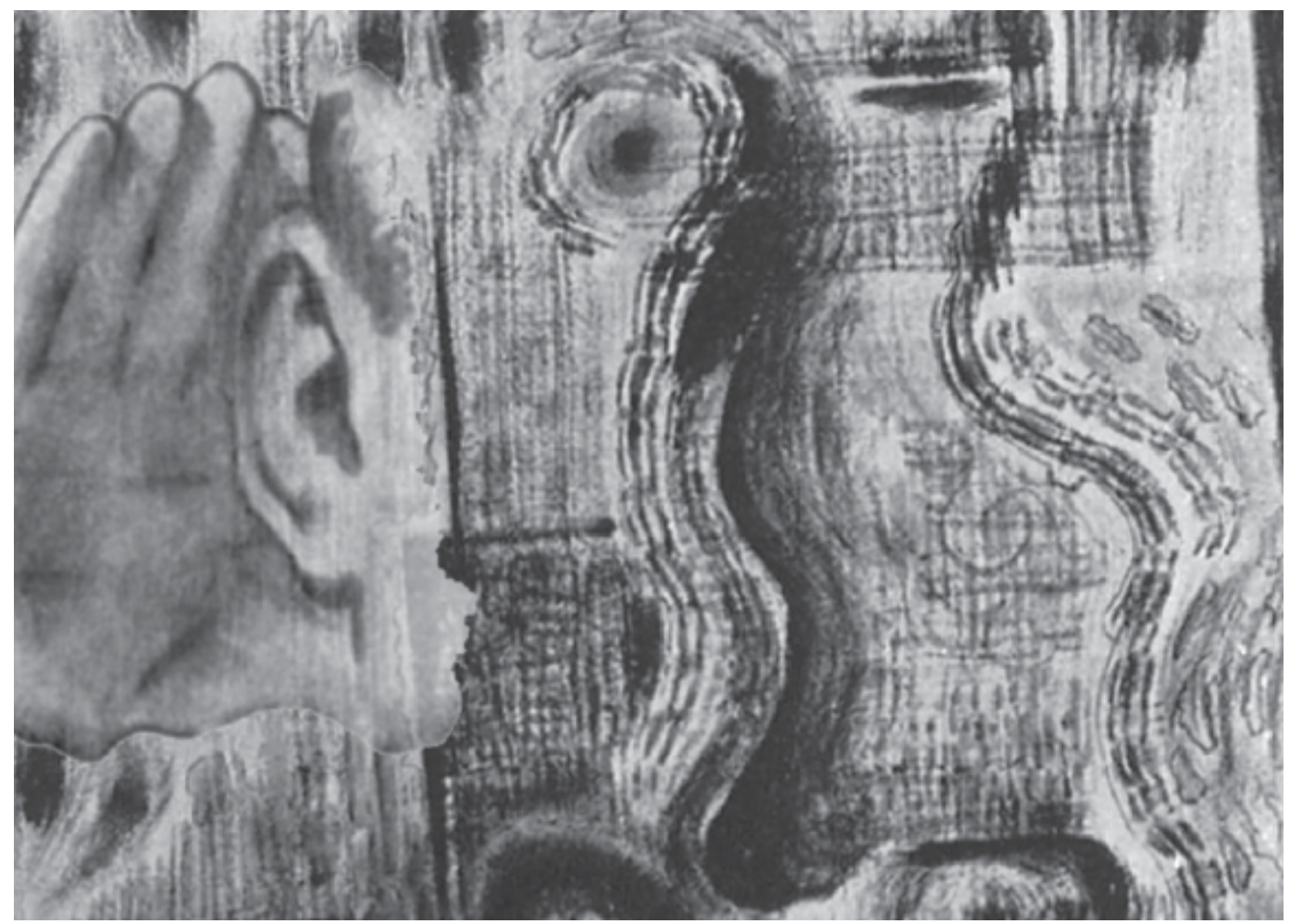


Identidade, Cultura Surda e Produção de Subjetividades e Educação:

Atravessamentos e Implicações Sociais

Eliane Maria Polidoro da Costa Cromack Rua Afonso Luiz Borba n. ${ }^{\circ} 154$ Lagoa da Conceição Cep.:88062-040 Florianópolis/SC

DORON, Roland; PAROT, Françoise. Dicionário de Psicologia. São Paulo: Ática, 2001.

FRANCO, Maria L. O que É Análise de Conteúdo. In Ensino Médio: Desafios e Reflexões. Campinas: Papirus, 1996.

GÓES, Maria Cecília Rafael. Linguagem, Surdez e Educação. 2. ed. São Paulo: Autores Associados, 1999.

GOLDFELD, Márcia. A Criança Surda: Linguagem e Cognição numa Perspectiva Socio-interacionista. 2. ed. São Paulo: Plexus, 2002.

GUARESCHI, Neuza. Políticas de Identidade: Novos Enfoques e Novos Desafios Para a Psicologia Social. Psicologia e Sociedade, 12, (1/2), jan./dez.2002, pp. 110-124.

JODELET, Denise. Os Processos Psicossociais da Exclusão. In Sawaia, B. As Artimanhas da Exclusão: Análise Psicossocial e Ética da Desigualdade Social. Petrópolis: Vozes, 1999. pp. 53 - 64 .

KAUCHAKJE, Samira. “Comunidade Surda”: as Demandas Identitárias no Campo dos Direitos, da Inclusão e da Participação Social. In Silva, Ivani Rodrigues, Kauchakje, Samira, Gesueli, Zilda Maria. Cidadania, Surdez e Linguagem: Desafios e Realidades. São Paulo: Plexus, 2003, pp. $57-67$.

LANE, Silvia Tatiana Maurer, SAWAIA, Bader Burihan. Novas Veredas da Psicologia Social. São Paulo, Brasiliense, 1995.

MAHEIRIE, Kátia. Agenor no Mundo: um Estudo Psicossocial da Identidade. Florianópolis: Letras Contemporâneas, 1994.
MASINI, Elcie F. Salzano (org). Do Sentido...Pelos Sentidos...Para o Sentido: Sentidos das Pessoas com Deficiência Sensorial. São Paulo: Vetor, 2002

PERLIN, Gladis T. T. Identidade Surda. In Skliar, C. (org.). A Surdez: um Olhar Sobre as Diferenças. Porto Alegre: Mediação, 1998, pp. 5172.

REGO, Teresa Cristina. Vygotski: uma Perspectiva Histórico-cultural da Educação. 3. ed. Petrópolis, RJ: Vozes, 1995.

SACKS, Oliver. Vendo Vozes: uma Viagem ao Mundo dos Surdos. São Paulo: Companhia das Letras, 1998.

SILVA, Tomaz Tadeu da. A Produção Social da Identidade e da Diferença. In Silva, Tomaz Tadeu da; Hall Stuart; Woodwart Kathryn. Identidade e Diferença: a Perspectiva dos Estudos Culturais. Petrópolis: Vozes, 2000.

SKLIAR, Carlos. Os Estudos Surdos em Educação: Problematizando a Normalidade. In __ (org.). A Surdez: um Olhar Sobre as Diferenças. Porto Alegre: Mediação, 1998, pp. 7-32.

VYGOTSKY, Liev Semiónovitch. AFormação Social da Mente: o Desenvolvimento dos Processos Psicológicos Superiores. 6. ed. São Paulo: Martins Fontes, 1998.

VIGOTSKI, Liev Semiónovitch. Teoria e Método em Psicologia. São Paulo: Martins Fontes, 1996.

VYGOTSKI, Lev S. Obras Escolhidas. Vol. V. Madrid: Visor, 1993.

Referências 